\title{
Performance characteristics of the spectral-amplitude-coding optical CDMA system based on one-dimensional optical codes and a multi-array laser
}

\author{
Teena Sharma and Ravi Kumar Maddila \\ Department of Electronics and Communication, Malviya National Institute of \\ Technology, Jaipur, India \\ e-mail2013rec9539@mnit.ac.in, rkmaddila.ece@mnit.ac.in
}

Received: 01.02 .2019

\begin{abstract}
We present a comparative analysis of performance characteristics of the optical code-division multiple-access systems, which are based on spectralamplitude coding (SAC) and are implemented using eight different one-dimensional optical codes and a multi-array laser. We try to find the best code for the SAC systems by taking into consideration such parameters as system requirements for the number of users, the data rate and the type of network suitable for a particular code. Our simulations reveal that the capacity of the SAC systems can be improved when those systems are implemented with a laser rather than incoherent light source. Moreover, we demonstrate that the laser-based SAC system performs well in terms of high data rates, which is followed by improved bit error rates occurring with increasing number of users. As a trade-off among different performance characteristics, different optical codes under analysis can be applied for different specific communication systems. The suggested codes support the maximal data rates up to $12 \mathrm{Gbps}$ for approximately 50 users. The maximal fibre length that supports error-free transmission is equal to $70 \mathrm{~km}$.
\end{abstract}

Keywords: SAC OCDMA, optical codes, multi-array lasers, detection techniques, bit-error rate, phase-induced intensity noise, modified double-weight codes.

UDC: 535.8

\section{Introduction}

Optical techniques have made communication systems much more efficient. Nowadays, scaling capacities of these systems need efficient management of the optical-fibre spectrum. To satisfy the bandwidth demands to the future information networks, enormous bandwidths of optical-fibre communication systems can be exploited to its maxima via multiplexing low-rate data streams into fibres [1]. In case of the access environment, where the cost is one of decisive factors, the optical code-division multiple-access (OCDMA) systems based upon spectral-amplitude coding (SAC) seem to be promising candidates for achieving higher data rates [2]. For the long-distance communications, coherent light sources must be incorporated in place of standard LED-based systems.

The OCDMA systems offer such advantages as asynchronous access, high bandwidth efficiency, high adequacy for bursty traffics, support of high data rates, and ability of easy adding of new channels [3]. Unfortunately, their main disadvantage is that they are affected by the effect of multiple-access interference (MAI) and the phase-induced intensity noise (PIIN), due to high cross-correlation between codes. In this respect, the SAC OCDMA represents a type of OCDMA in which the frequency components of a signal passed from a broadband optical source are 
encoded using selective blocking or transmitting in accordance with a signature code. This technique eliminates the MAI when the codes with fixed in-phase cross-correlation and zero crosscorrelation are used as address sequences [4].

Both the simulation and experimental works published previously on the SAC have typically employed incoherent broadband sources. The principal limitation of these light sources is that they provide low data rates when long distances of communications is a major factor and a highintensity noise is present because of incoherency of a broadband spectrum [5]. To bypass this shortcoming, a number of previous studies have suggested multi-wavelength laser sources (laser arrays) to achieve higher performance $[6,7]$, although the performance attainable in this manner has not been examined. These analyses are important since the lasers support higher data rates. Indeed, a coherent light source which can generate a huge number of wavelengths represents a cost-effective approach [8]. A choice of laser instead of LED in fibre-optical communications depends on many factors such as target application, related performance and reliability requirements to the communication system.

As a consequence, the main objective of this study is to analyze the performance of the recently developed one-dimensional optical codes combined with the multi-array laser sources for the SAC systems, in particular the consideration in terms of the data rates achievable with increasing communication distance. We also plan to discuss the types of optical sources and their selection criteria following from specific implementations of the SAC systems, as well as to analyze the corresponding simulation results by comparing the performances of different code.

\section{Types of optical sources and criteria for their selection}

\subsection{Incoherent sources}

White-light LEDs are highly preferred sources for the SAC systems due to their wider bandwidths and incoherence associated with a wide spectrum. Moreover, due to such properties as little temperature dependence and simple drive circuits, these sources are suitable for relatively short communication distances. The performance of the systems is limited to hundreds of Mbps due to a non-uniform power distribution of the spectral bandwidth of such sources, which results in MAI. Beating of different optical frequencies in the optical-signal bandwidth causes a beat noise and an intensity noise, which also affect the performance characteristics.

\subsection{Coherent sources}

Laser sources are highly chromatic and reveal very narrow spectral widths, if compared to LEDs. They also allow a wide variety of modulation types such as differential-phase, quadrature-phase and frequency-shift keyings. The signal can be modulated at high bit rates and transferred over long distances [9]. The cost of the laser increases with increasing number of its wavelengths. Moreover, directly modulated lasers can be used in the high-speed fibre-optic transmission systems, with the data rates up to $12 \mathrm{Gbps}$. Due to their cost effectiveness and less power consumption, the transmitters based on directly modulated lasers can be easily miniaturized, unlike those based on externally modulated LEDs. Moreover, further improvements in the dispersion tolerance of high-speed transmission links are also possible with the directly modulated lasers [7]. Of course, each of the schemes has its merits and demerits, so that one has to choose a suitable scheme for a specific application. Table 1 compares the main features, the factors of design and the criteria needed to select the laser-based or the LED-based systems [10]. 
Table 1. Comparison of lasers and LEDs as optical sources for the fibre-optical communications [10].

Characteristics LED Laser

\begin{tabular}{|c|c|c|}
\hline Spectral width & Wider $(25-100 \mathrm{~nm})$ & Narrower $(1-2 \mathrm{~nm})$ \\
\hline $\begin{array}{l}\text { Modulation } \\
\text { speed }\end{array}$ & Slower (100-300 MHz) & Faster (e.g., $1 \mathrm{GHz}$ or higher) \\
\hline $\begin{array}{c}\text { Optical } \\
\text { bandwidth }\end{array}$ & 40 to $100 \mathrm{~nm}$ & $<1 \mathrm{~nm}$ \\
\hline Output power & $\begin{array}{l}\text { Depends on the speed; limited to } \\
\quad \sim 40 \mathrm{~mW} \text { for high speeds }\end{array}$ & $\begin{array}{l}\text { Hundreds of mW available; optical } \\
\text { amplification }\end{array}$ \\
\hline E/O efficiency & Lower $(10-20 \%)$ & Higher $(30-70 \%)$ \\
\hline Driving current & Higher (50-100 mA) & Lower $(5-40 \mathrm{~mA})$ \\
\hline $\begin{array}{l}\text { Coherence and } \\
\text { directionality }\end{array}$ & Essentially incoherent & Coherent and highly directional \\
\hline $\begin{array}{l}\text { Spectral } \\
\text { spreading }\end{array}$ & Higher & Lower \\
\hline System cost & $\begin{array}{l}\text { Low-cost and off-the-shelf } \\
\text { optics and electronics }\end{array}$ & $\begin{array}{l}\text { High- and especially high-grade optics } \\
\text { and compensating electronics }\end{array}$ \\
\hline Gain & Lower & Higher \\
\hline Applications & $\begin{array}{l}\text { Fibres for the home and local- } \\
\text { area networks }\end{array}$ & $\begin{array}{l}\text { Long-haul applications such as } \\
\text { metropolitan-area networks }\end{array}$ \\
\hline
\end{tabular}

\section{Implementation of SAC OCDMA system with a multi-laser source}

A block diagram of our SAC OCDMA system is shown in Fig. 1. At the receiving side, the incoming signal is first split and then sent to the decoding section of each user. The code is generated by selecting the wavelengths from the optical signal of a multi-array laser source, whereas the wavelengths are selected according to the code transmitted over the channel. These signals are modulated according to the given data, using a Mach-Zehnder modulator. The codes from different users are combined before launching them into the fibre. At the receiver side, the signals are split with a demultiplexer, and an authorized user can extract the original data using a direct-detection filter method.

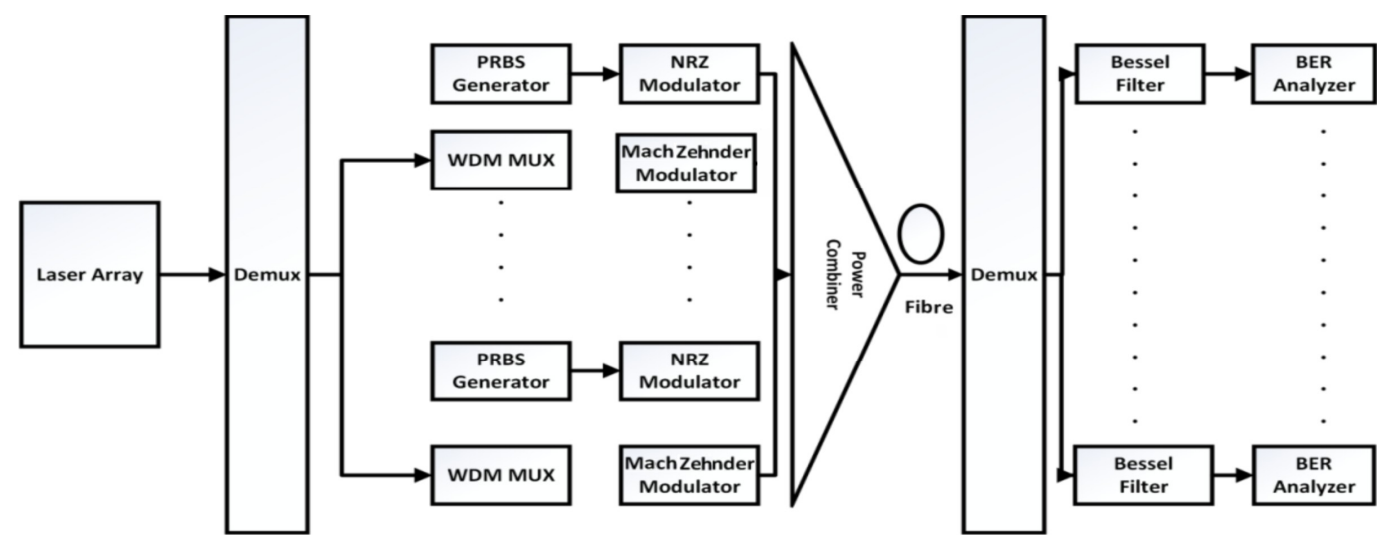

Fig. 1. Setup of our SAC OCDMA system based on a multi-array laser source. 


\subsection{Simulation software}

We compare the SAC OCDMA systems designed using a multi-array laser and eight different codes: multi-diagonal (MD), single-weight zero cross-correlation, flexible cross-correlation, multiidentity high-power, enhanced double-weight, random diagonal, diagonal double-weight ones, and a so-called 'diagonal eigenvalue unity' code. All of these codes have been simulated using Optisystem 13 simulation software. In our simulations seven user networks are considered. Fig. 2 and Fig. 3 display respectively the encoder and decoder of the SAC OCDMA system. It utilizes the MD code, the weight $W=3$ and the cardinality $K=7$. The code is repeated four times in a given wavelength domain to support seven users.

A continuous-wave laser based on emitting-surface semiconductor technology [11] is used to generate chirps spaced with the gaps $0.8 \mathrm{~nm}$. The data rate $r=10 \mathrm{Gbps}$, the transmittance distance $l=50 \mathrm{~km}$ and a standard single-mode fibre ITU T G-52 are taken. A transmitter for each user consists of a continuous-wave laser array, with each laser operating at the input power $0 \mathrm{~dB} \times \mathrm{m}$. The signal accumulated from the laser array is initially multiplexed, using an ideal multiplexer. Then it is modulated with a pseudo-random bit-sequence generator based on the output data. A pseudorandom bit-sequence source produces random binary sequences. A Mach-Zehnder modulator is used with the extinction ratio $30 \mathrm{~dB} \times \mathrm{m}$. Note that each chirp has the spectral width $0.8 \mathrm{~nm}$.

The design of our receiver is shown in Fig. 3. A decoder with a single-photon diode-detection technique $[11,12]$ is implemented, using standard photodiodes and an electrical filter of the receiver. The latter represents a low-pass optical Bessel filter of the fourth order with the electrical bandwidth equal to $75 \%$ of the data rate. Optical signals are detected using a PIN photodiode detector. To obtain a desired output, the Bessel filter is placed at the end of the receiving side. Multiplexer and demultiplexer are used to combine and separate optical chips as a coded sequence by setting the optical bandwidth to $30 \mathrm{~nm}$.

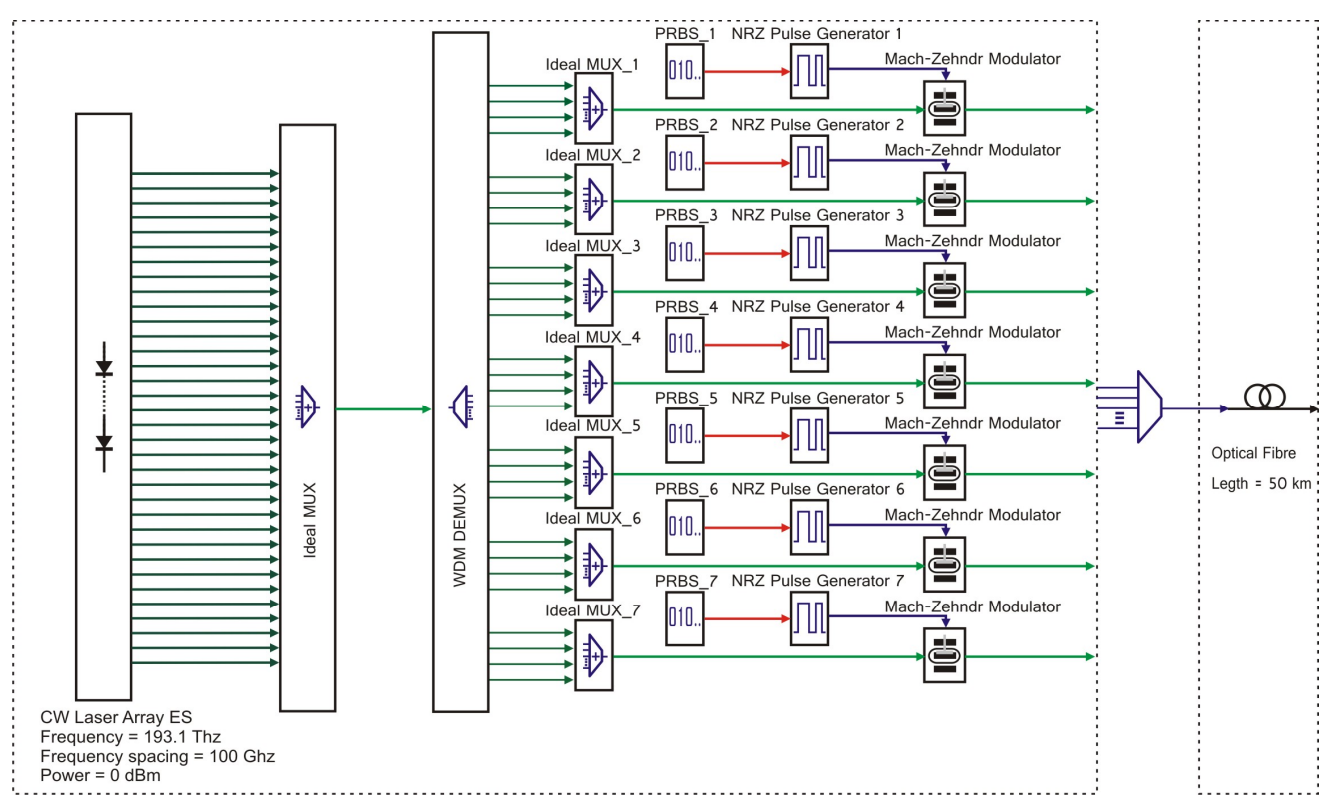

Fig. 2. SAC OCDMA encoder with MD code and a multi-laser source.

\subsection{Error probability for the $M D$ code}

For the case of $K=7$ and $W=3$, the general relation among the code length $L$, the number of users $K$, and the weight $W$ is as follows: 


$$
L=K W=21 \text {. }
$$

Using the properties of the MD code, one can write out the corresponding signal-to-noise ratio as [12]

$$
S N R=\frac{\left(\frac{K P_{s r} W^{2}}{N}\right)^{2}}{\frac{e B K P_{s r} W^{2}}{N}+\frac{4 K_{b} T_{n} B}{R_{L}}},
$$

where $e$ is the electron charge, $B$ the electrical bandwidth of receiver $(311 \mathrm{MHz}), P_{s r}$ the effective source power $(0 \mathrm{~dB} \times \mathrm{m}), T_{n}=300 \mathrm{~K}$ the absolute noise temperature of receiver, $K_{b}$ the Boltzmann's constant, and $R_{L}$ the load resistor of receiver $(1030 \Omega)$.

Use of the signal-to-noise ratio in calculating the bit error rate (BER) represents a standardized technique, which is particularly valuable if one analyzes different codes. The BER can be calculated following from the Gaussian approximation [13]:

$$
B E R=P_{e}=\frac{1}{2} \operatorname{erfc}\left(\sqrt{\frac{S N R}{8}}\right) .
$$

Here the probability of error $P_{e}=E_{b} / N_{o}$ represents the ratio of the average bit energy $E_{b}$ to the spectral power density $N_{o}$ of noise, and erfc denotes the complementary error function. This gives us the relative number of errors occurring during transmission. According to its construction, the BER relies upon the signal and noise powers or the signal-to-noise ratio. If the number of users, the code weight and the code length are described by Eq. (1), the code sequences used for seven users and the MD code are depicted in Table 2.

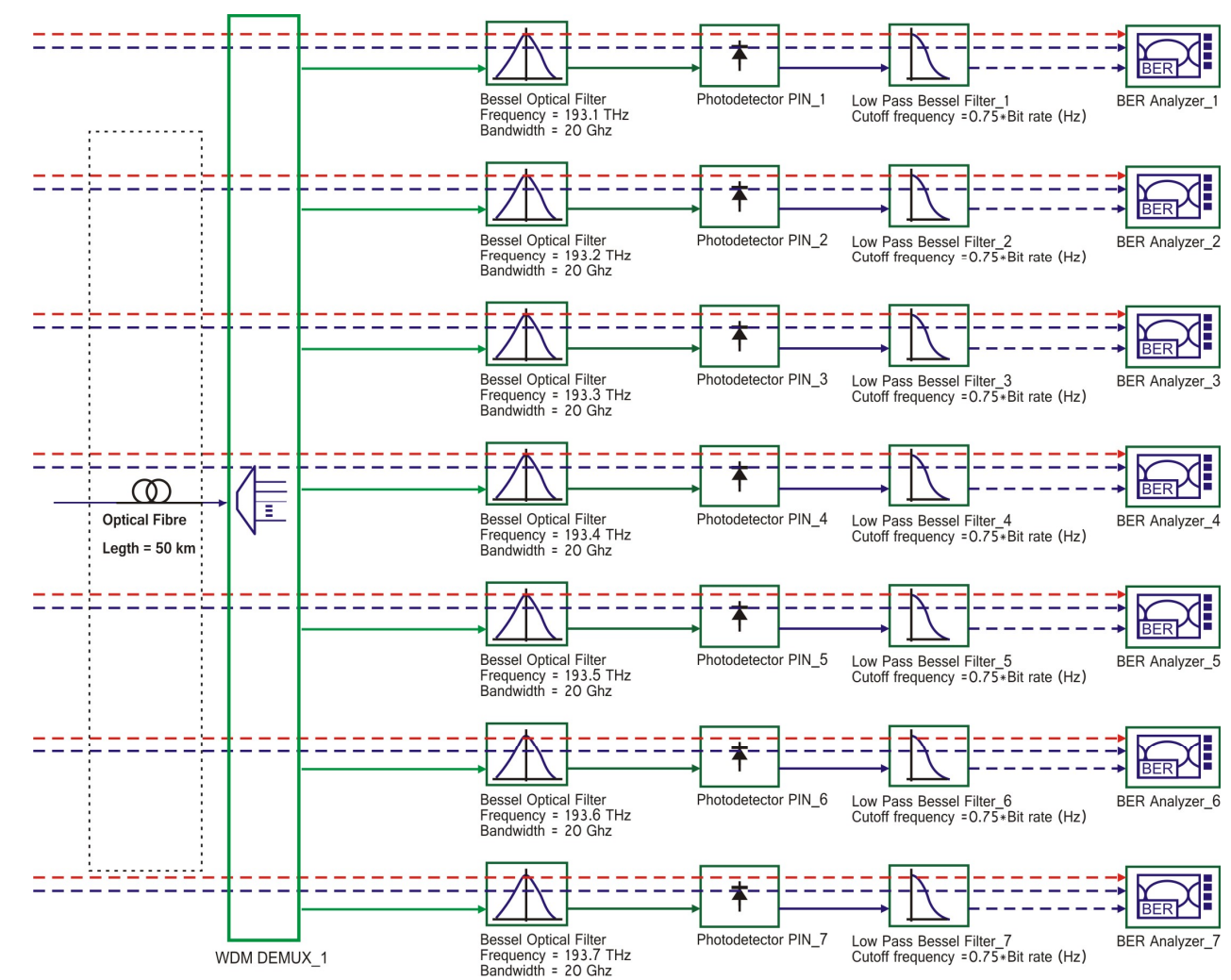

Fig. 3. SAC OCDMA decoder with MD code and a multi-array laser. 
Table 2. MD code employed for seven users.

$\left|\begin{array}{lllllllllllllllllllll}1 & 0 & 0 & 0 & 0 & 0 & 0 & 0 & 0 & 0 & 0 & 0 & 0 & 1 & 1 & 0 & 0 & 0 & 0 & 0 & 0 \\ 0 & 1 & 0 & 0 & 0 & 0 & 0 & 0 & 0 & 0 & 0 & 0 & 1 & 0 & 0 & 1 & 0 & 0 & 0 & 0 & 0 \\ 0 & 0 & 1 & 0 & 0 & 0 & 0 & 0 & 0 & 0 & 0 & 1 & 0 & 0 & 0 & 0 & 1 & 0 & 0 & 0 & 0 \\ 0 & 0 & 0 & 1 & 0 & 0 & 0 & 0 & 0 & 0 & 1 & 0 & 0 & 0 & 0 & 0 & 0 & 1 & 0 & 0 & 0 \\ 0 & 0 & 0 & 0 & 1 & 0 & 0 & 0 & 0 & 1 & 0 & 0 & 0 & 0 & 0 & 0 & 0 & 0 & 1 & 0 & 0 \\ 0 & 0 & 0 & 0 & 0 & 1 & 0 & 0 & 1 & 0 & 0 & 0 & 0 & 0 & 0 & 0 & 0 & 0 & 0 & 1 & 0 \\ 0 & 0 & 0 & 0 & 0 & 0 & 1 & 1 & 0 & 0 & 0 & 0 & 0 & 0 & 0 & 0 & 0 & 0 & 0 & 0 & 1\end{array}\right|$

\section{Simulations and numerical results}

We have compared the performance characteristics of the optical codes under test, using the simulation parameters presented in Table 3. Fig. 4a shows the dependences of the quality factor $Q$ on the fibre distance for all of the eight codes under analysis. The minimal $Q$ value achieved at the fibre distance $50 \mathrm{~km}$ in the case of error-free transmission is about 8 . It is peculiar for the diagonal eigenvalue unity code. The MD code reveals the highest $Q$ factor $(Q=22)$ at the same distance and the transmission rate $10 \mathrm{Gbps}$. We observe that, owing to its optimal performance in terms of a number of parameters under test (see also Fig. 4a), the MD code is the best suited for the SAC systems. Moreover, the corresponding code construction is simple and easy enough to be extended to greater numbers of users.

Table 3. Parameters used in our simulations of the SAC OCDMA system based on a laser array and different codes.

\begin{tabular}{cc} 
Parameter & Value \\
\hline Electrical bandwidth $B$ & $311 \mathrm{MHz}$ \\
Effective laser power $P_{s r}$ & $0 \mathrm{dBm}$ \\
Operating wavelength $\lambda_{o}$ & $1550 \mathrm{~nm}$ \\
Receiver noise temperature $T_{n}$ & $300 \mathrm{~K}$ \\
Receiver load resistor $R_{L}$ & $1030 \Omega$ \\
Optical bandwidth $B_{o}$ & $3.17 \mathrm{THz}$ \\
\hline
\end{tabular}

Fig. $4 \mathrm{~b}$ depicts the dependences of the BER on the fibre distance. The performance of the MD code with the single-photodiode detection technique is better than that found for the other codes. Here the diagonal eigenvalue unity code supports the lowest BER, due to increased crosscorrelation factor among the users. We remind that the active number of users and the communication speed are equal respectively to 7 and $10 \mathrm{Gbps}$. Fig. 4c shows the dependences of the $Q$ factor on the number of users for different codes. The performance of the MD code is evidently better than that of the multi-identity high-power one. However, the latter generally provides some advantage in the bandwidth efficiency due to its less code length. Our results testify that the performance of the SAC system with the diagonal eigenvalue unity code decreases due to high cross-correlation value $\left(\lambda_{c}=2\right)$. Since the single-weight zero cross-correlation code has multiple 1 's in the code matrix at the adjacent places, its performance is lower, if compared to both the multi-identity highpower code and the MD code (see Fig. 4c). This degrades the performance of the SAC system because of the MAI, which results in a low signal-to-noise ratio. Moreover, the nonlinear effects are also initiated due to high power of the adjacent signals. As a result, one can observe an increase in the performance and then its sharp decrease, which surpasses the curve for the flexible cross-correlation code. Furthermore, our results indicate that, if compared to the other codes, the performance of the MD code is superior due to its highest supported number of users and a 
satisfactory $Q$ factor. Finally, the MD code reveals a zero cross-correlation property and no MAI.

Fig. 4d and Fig. 4e illustrate the data for the $Q$ factor and the BER as functions of the data rate. Short code length is typical for the flexible cross-correlation code with a high cross-correlation $\left(\lambda_{c}=2\right)$. The interference increases for shorter code lengths and higher cross-correlations. Similarly, longer code length for the enhanced double-weight code is observed at the unit crosscorrelation. Moreover, the corresponding complexity increases with increasing number of users.

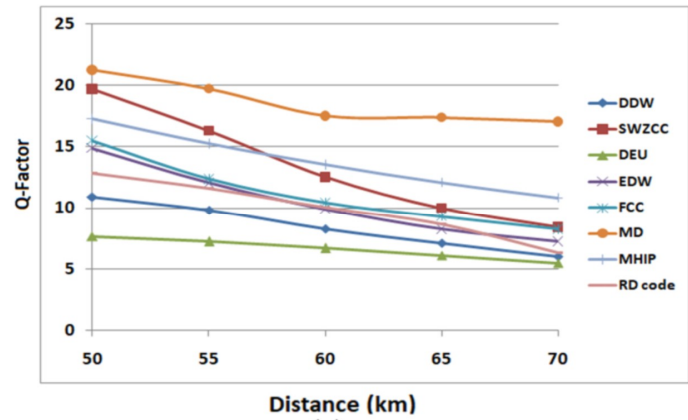

(a)

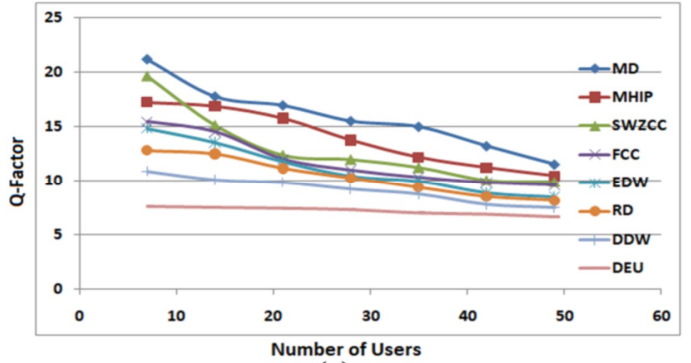

(c)

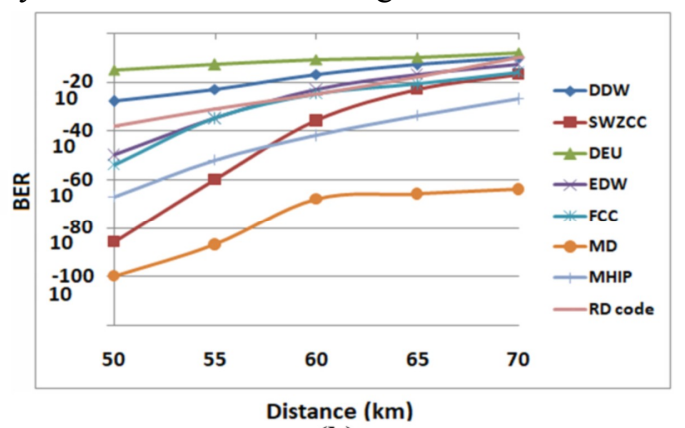

(b)

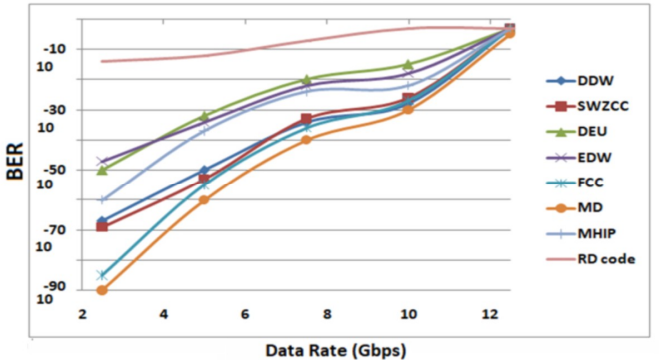

(d)

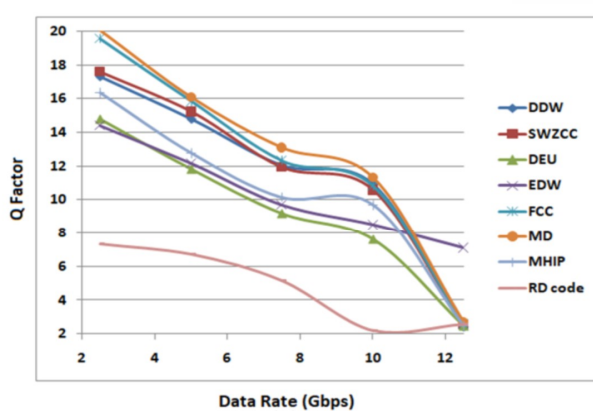

(e)

Fig. 4. Dependences of $Q$ factor and BER on the transmission distance $l$, number of users $K$ and data transmission rate $r$, as simulated for different SAC codes: (a) $Q(I)$, (b) BER(l), (c) $Q(K)$, (d) BER(r), and (e) $Q(r)$.

The length of the random diagonal code is comparatively short at the unit cross-correlation. Minimal code length and maximal bandwidth efficiency are observed for the diagonal doubleweight code. The observed signal power is low due to a presence of only two wavelengths in a single-user code. This provides a low quality factor $Q$ and a high BER for the diagonal doubleweight code. In addition, longer code length is observed in case of the diagonal eigenvalue unity code, under the condition of unit cross-correlation. Our results also testify that the interference increases in the presence of adjacent signals, due to construction of the diagonal eigenvalue unity code. The MD code provides the highest performance in terms of the BER $\left(10^{-29}\right)$ at the data rate $r=10 \mathrm{Gbps}$ analyzed in the present work. Finally, in Table 4 we summarize different characteristics of the codes under our analysis, which have been derived in this work. 


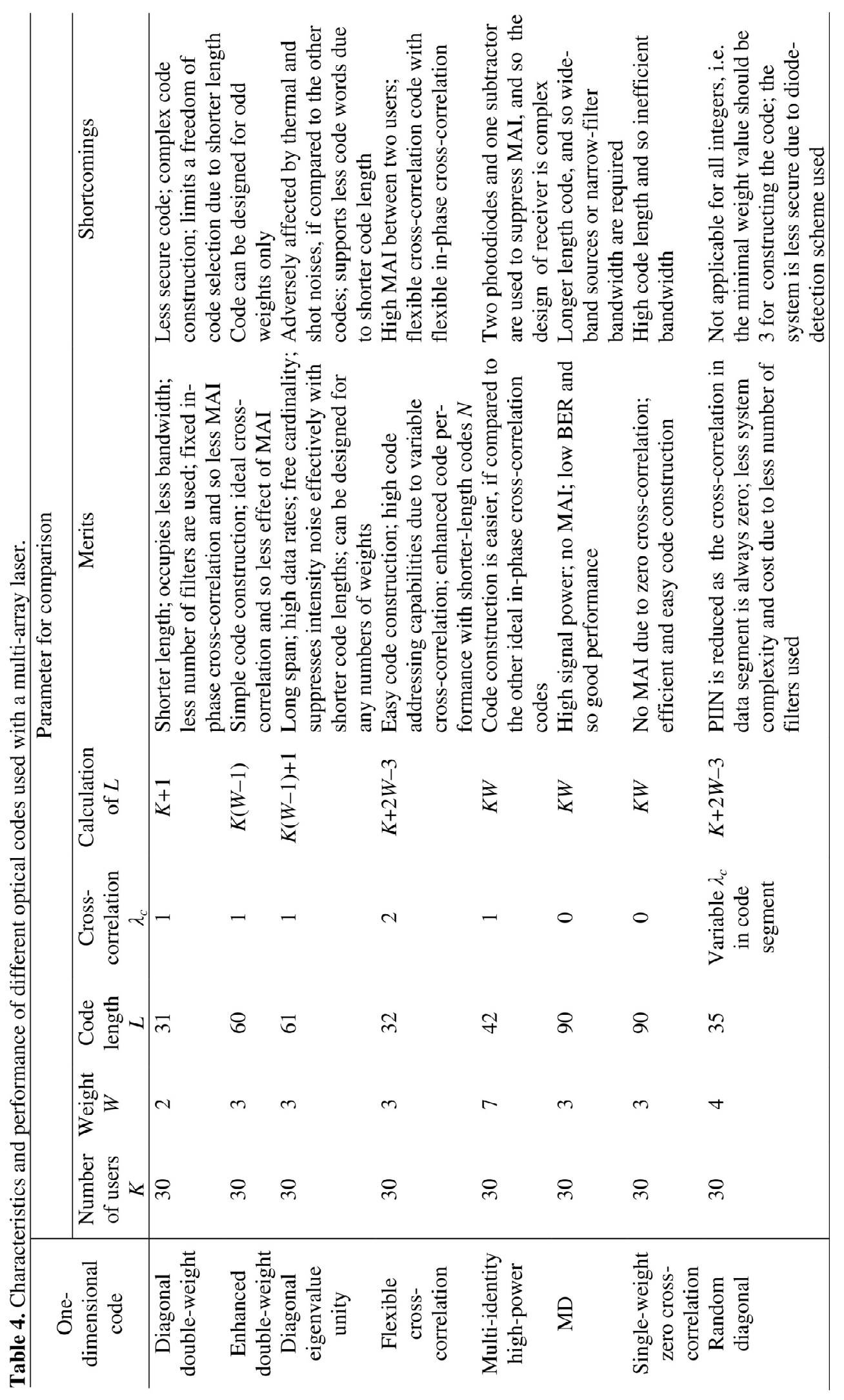




\section{Conclusions}

In the present work we report a comparative analysis of eight one-dimensional SAC codes used in the OCDMA systems. The performances of these codes have been studied under condition when a multi-array laser is employed as a light source in the communication system. The BER of the codes is evaluated using the simulation experiments. Our simulations have testified that some of the codes under analysis can improve the performance in terms of the BER parameter and the data transmission speed. As a kind of trade-off among different characteristics of the system, different codes can be used for different specific applications. The diagonal double-weight code proves to be optimal in terms of its bandwidth efficiency and some other reasoning such as low cost and easy code construction. It is also clear that the MD code is superior in terms of the system performance due to its zero cross-correlation properties. However, its bandwidth remains inefficient due to a longer code length.

Our simulation results have revealed that the laser-based systems support higher data rates, longer-distance signal transmission and higher signal-to-noise ratios at larger cardinalities. Here the direct-detection technique implies a less number of photodiodes for the system due to cost effectiveness and less complexity. Some previous studies have reported that the systems with coherent sources are characterized by a high cost whenever one laser is used for one wavelength. Nonetheless, in the light of novel developments of cost-effective multi-wavelength lasers and directly modulated lasers, as well as huge improvement in vertical-cavity surface-emitting laser arrays $[14,15]$, the results of the present study seem to be promising. Another important implication of our results is that good codes with a less number of weights can be designed, which can compensate the cost factor.

Finally, our study suggests a need in future work concerned with high-performance unipolar codes and their numerical performance comparisons. This work can be further extended to the case of two-dimensional codes associated with multi-array laser sources, in order to achieve higher cardinality and data rates.

\section{References}

1. Farhat A, Menif M, Lepers C, Rezig H and Gallion P, 2008. Performance comparison of coherent versus incoherent direct sequence optical code division multiple access system. In: Photonics North, Vol. 7099, p. 70991N.

2. Alhassan A M, Badruddin N, Saad N M and Aljunid S A, 2013. Enhancing the performance of coherent sources SAC OCDMA networks via spatial multiplexing. J. Opt. Soc. Korea. 17: $471-480$.

3. Karafolas $\mathrm{N}$ and Uttamchandani D, 1996. Optical fiber code division multiple access networks: A review. Opt. Fiber Technol. 2: 149-168.

4. Abd T H, Aljunid S A, Fadhil H A, Radhi I F, Ahmad R B and Rashid M A, 2012. Performance improvement of hybrid SCM SAC-OCDMA networks using multi-diagonal code. Sci. Res. Essays. 7: 1262-1272.

5. Al-Khafaji H M, Aljunid S A and Fadhil H A, 2012. Improved BER based on intensity noise alleviation using developed detection technique for incoherent SAC-OCDMA systems. J. Mod. Opt. 59: 878-886.

6. Ayotte S and Rusch L A, 2007. Increasing the capacity of SAC-OCDMA: Forward error correction or coherent sources? IEEE J. Select. Topics in Quant. Electron. 13: 1422-1428.

7. Krehlik P, 2009. Improvement in dispersion tolerance of high-speed fiber optic transmission link by optimization of laser modulation. Opto-Electron. Rev. 17: 225-230. 
8. Mamdoohi G, Sarmani A R, Abas A F, Yaacob M, Mokhtar M and Mahdi M A, 2013. 20 $\mathrm{GHz}$ spacing multi-wavelength generation of Brillouin-Raman fiber laser in a hybrid linear cavity. Opt. Express. 21: 18724-18732.

9. Dai B, Gao Z, Wang X, Kataoka N and Wada N, 2011. A novel optical orthogonal modulation format based on differential phase-shift keying and code-shift keying. IEEE Photon. Technol. Lett. 23: 1210-1212.

10. Fadhil H A, Aljunid S A and Ahmad R B, 2010. Design considerations of high performance optical code division multiple access: a new spectral amplitude code based on laser and light emitting diode light source. IET Optoelectron. 4: 29-34.

11. Al-Khafaji H M, Amphawan A and Fadhil H A, 2012. Improving spectral efficiency of SACOCDMA systems by SPD scheme. IEICE Electron. Express. 9: 1829-1834.

12. Norazimah M Z, Aljunid S A, Fadhil H A and Zain A M, 2011. Analytical comparison of various SAC-OCDMA detection techniques. In: $2^{\text {nd }}$ IEEE Int. Conf. on Photonics, pp. 1-5.

13. Wei $Z$ and Ghafouri-Shiraz H, 2002. Unipolar codes with ideal in -phase cross-correlation for spectral-amplitude-coding optical CDMA system. IEEE Trans. Commun. 50: 1209-1212.

14. Smith E D, Blaikie R J and Taylor D P, 1998. Performance enhancement of spectralamplitude-coding optical CDMA using pulse-position modulation. IEEE Trans. Commun. 46: 1176-1185.

15. Sciancalepore C, Bakir B B, Menezo S, Letartre X, Bordel D and Viktorovitch P, 2013. III-Von-Si photonic crystal vertical-cavity surface-emitting laser arrays for wavelength division multiplexing. IEEE Photon. Technol. Lett. 25: 1111-1113.

Teena Sharma and Ravi Kumar Maddila. 2019. Performance characteristics of the spectralamplitude-coding optical CDMA system based on one-dimensional optical codes and a multi-array laser. Ukr.J.Phys.Opt. 20: 81 - 90. doi: 10.3116/16091833/20/2/81/2019

\begin{abstract}
Анотація. Представлено порівняльний аналіз характеристик оптичних систем множинного доступу з кодовим розділенням, які засновані на спектрально-амплітудному кодуванні (САК) і реалізовані з використанням восьми різних одновимірних оптичних кодів $i$ матричного лазера. Ми намагалися знайти найкращий код для систем САК, враховуючи такі параметри як системні вимоги до кількості користувачів, швидкості передавання даних і типу мережі, придатного для конкретного коду. Наше моделювання показало, щзо інформаційну ємність систем САК можна поліпшити, якщо иі системи засновані на лазерах, а не на некогерентних джерелах світла. Крім того, продемонстровано, щзо САК, заснована на лазері, добре прачює з точки зору високих швидкостей передавання даних, щяо супроводжується також пониженням частоти появи бітових помилок зі збільшенням кількості користувачів. Як компроміс між різними характеристиками, для різних конкретних систем комунікацій можна застосовувати різні проаналізовані нами оптичні коди. Запропоновані коди підтримують максимальну швидкість передачі даних до 12 Гбіт/с для приблизно 50 користувачів. Максимальна довжина волокна, яка підтримує безвідмовне передавання даних, дорівнює 70 км.
\end{abstract}

